\title{
Sobre a constituição do ensino institucionalizado de português no Brasil: o estilo e a produção de uma memória em Infância, de Graciliano Ramos
}

\section{On the constitution of Portuguese teaching in Brazil: stylistics and the production of a memory in Infância, by Graciliano Ramos}

\author{
Émerson de Pietri ${ }^{1}$
}

\begin{abstract}
RESUMO
Historicamente, a produção literária brasileira, em sua função de constituição de uma cultura escrita com base no tratamento estilístico dos recursos linguísticos em circulação na heterogeneidade social, materializou representações sobre a formação do processo de escolarização do ensino de língua materna no país, com o que se compuseram documentos para uma memória da educação linguística no Brasil. Com o objetivo de conhecer os modos de constituição da escola e do ensino de português, no Brasil, e considerada a produção literária como fonte de dados para esse processo investigativo, observa-se, neste estudo, a representação da escola e do ensino de língua portuguesa em Infância, de Graciliano Ramos, obra em que se encontram registros do processo de institucionalização da educação e do ensino de língua num momento e numa localidade brasileiros.

Palavras-chave: ensino de português; formação e memória; literatura; letramento; estilo; discurso.
\end{abstract}

\section{ABSTRACT}

In this paper, literary representations of Brazilian school and of the teaching of Portuguese are observed. For the analysis presented in this work, literary

DOI: $10.1590 / 0104-4060.39725$

1 Universidade de São Paulo. Faculdade de Educação. São Paulo, São Paulo, Brasil. Avenida da Universidade, n 308. CEP: 05508-040.E-mail: pietri@usp.br 
text is not considered as only a registration of historical facts, but also as a product of writer's formal solutions in his task to configure language as a discursive object. In this way, a chapter of Graciliano Ramos' Childhood is analyzed in order to characterize a specific moment of Portuguese teaching history in Brazil: the first Republican period and its project for public Education, in the last years of the 19th century and first decades of the 20th.

Keywords: Portuguese research and teaching; formation and memory; literature; literacy; stylistics; discourse.

\section{Introdução}

O presente trabalho se insere num percurso de pesquisa em que se observam os modos como se constrói, historicamente, no Brasil, a representação do que seja a língua portuguesa em sua modalidade escrita, seu ensino, e as práticas letradas que nela se fundamentam, principalmente as associadas à instituição escolar em sua função de agência de letramento.

A história do ensino de língua portuguesa tem merecido o interesse de pesquisadores, que observam de que modo se constituíram historicamente os objetos, os métodos e a configuração da própria disciplina curricular. (SOARES, 2002; MORTATTI, 2000; PIETRI, 2007, 2010). Prevalece nos trabalhos que têm sido desenvolvidos sobre o tema, porém, uma perspectiva mais distanciada da cultura escolar e mais próxima dos condicionamentos acadêmicos, pedagógicos e oficiais em que se produziram, em momentos históricos determinados, e em lugares de proximidade com os centros de decisão política, mudanças nas concepções sobre o que seria (ou deveria ser) o ensino e a aprendizagem institucionalizados de língua portuguesa.

Assim, no presente trabalho, pretende-se contribuir para os estudos sobre a história do ensino de língua portuguesa no Brasil com a observação de fatos da cultura escolar que se possam entrever em realidades diversas daquelas mais próximas do controle institucional e, portanto, mais sujeitas aos efeitos dos projetos de escolarização estabelecidos em instâncias oficiais e acadêmicas, ou em instituições associadas a fins doutrinários, principalmente os religiosos. Mais distantes dos centros de decisão política, experiências de ensino escolarizado se mostram mais explicitamente em seu caráter híbrido, mestiço (VIDAL, 2009), que são condições para a produção de práticas culturais específicas.

Neste momento, objetiva-se ampliar os conhecimentos sobre o processo histórico de formação da cultura escolar e da oferta de educação linguística no 
Brasil, observando-se a representação desse processo para um momento e um lugar específicos do país: a passagem do Império à República, em finais do século XIX, longe dos centros econômicos e de decisão política, no interior do Nordeste, nos Estados de Pernambuco e de Alagoas. Para tanto, recorre-se à representação literária, em Infância ([1945] 1981), de Graciliano Ramos, em que se reúnem o estilístico e o histórico num trabalho de caráter autobiográfico.

Trata-se de observar a caracterização de tais práticas escolares no momento em que se desenvolvem ações de implantação da escola para a modernização do país, mas vistas pelo olhar do escritor, que se volta para suas memórias num tempo em que o projeto modernizador republicano se mostra mais desenvolvido. O olhar de Graciliano Ramos, nas memórias de Infância, ao se produzir nos anos 1940 do século XX, se faz do interior de um projeto de criação literária da realidade brasileira já definitivamente estabelecido, o modernismo, e num momento em que a configuração institucional, projetada em discursos oficiais (legais) e/ou acadêmicos, para a escolarização, se mostra em pleno desenvolvimento nos principais centros urbanos de vários Estados brasileiros, o que se evidencia, por exemplo, no movimento da Escola Nova e perspectivas concorrentes. (VIDAL, 2013).

Porém, a representação de uma escola em sua configuração de um momento anterior, o final do século XIX, possibilita acessar a memória que lhe constitui, de modo que a caracterização da cultura escolar em questão remete também às relações dessa cultura com o que lhe precede, no caso, às formas de escolarização primária estabelecidas no período monárquico. A análise dos dados permite, assim, perceber a escola tanto a partir de sua projeção no discurso modernizador republicano, quanto no que ela guarda de sua constituição no período do Brasil Império. (SCHUELER; MAGALDI, 2009).

A construção da escola moderna se faz para estabelecer a racionalidade do tempo e do espaço, de modo a se garantir mais eficiência, tanto acadêmica, quanto econômica (considerada a necessidade de financiamento da escola pelo poder público), bem como o distanciamento entre o mundo escolar e o mundo doméstico e religioso. Permanecem, no entanto, nos lugares não alcançados pelo raio de ação dos poderes públicos centrais, as escolas isoladas, instaladas em espaços distintos dos projetados para a escola moderna (e seus prédios desenhados para garantir a separação entre exterior e interior da escola), em edificações sem nenhuma condição para acomodar professor e alunos, ou nas residências dos próprios professores, em que vida doméstica e espaço público se imiscuíam. (LIMA; GATTI JR, 2008; LIMA; PINHEIRO, 2008). É desse impasse no processo de institucionalização do espaço escolar, em que pouco se divisa a separação entre o público e o privado, projetada nas regras do discurso modernizador republicano, que se trata no capítulo de Infância aqui analisado. 
A observação dos modos de representação da escola e do ensino de língua portuguesa, na narrativa de Infância, se faz especialmente interessante em razão de como nela o processo enunciativo se constitui a base para o tratamento dos limites institucionais e discursivos (ou da ausência desses limites, quando a escola pública, leiga e gratuita, prevista pela República, começava a se instituir no país), num determinado momento histórico e num espaço regional específico, entre instituições como a família e a escola, e, em relação a elas, entre práticas cotidianas, pedagógicas, literárias e científicas.

Nessa obra compõe-se uma representação das condições de escolarização, do ensino institucionalizado de língua portuguesa e das relações entre uma cultura acadêmica e a heterogeneidade cultural, com o que se pode ampliar a compreensão sobre como teriam se realizado as ações de ensino e de aprendizagem em lugares diversos no país, em diferentes épocas. Como se trata de observar de uma perspectiva histórica o que é da cultura escolar, o acesso a essa cultura se faz por intermédio de registros que possibilitem acessar marcas dessa cultura em momentos históricos determinados, que possibilitem construir estratégias metodológicas para compreender o que se constitui no interior dessa "caixa preta". (VIDAL, 2009).

O documento literário de caráter autobiográfico oferece acesso, assim, a dados que podem contribuir para o conhecimento a respeito do processo histórico de formação da cultura letrada e da cultura escolar no Brasil.

No caso da obra aqui analisada, o trabalho linguístico do sujeito que produz sua autobiografia, projetado entre a distinção e a indistinção, a precisão e a imprecisão, a definição e a indefinição, em relação aos fatos que traz para a elaboração escrita de uma vivência passada, seria não apenas um modo de representar o que é preciso recuperar a uma memória psicológica com suas limitações naturais, mas teria função estrutural na narrativa, operando para garantir filiação histórica ao trazido pela memória psicológica, e legitimidade discursiva ao que foi elaborado textualmente com os recursos da linguagem verbal.

Note-se, nesse sentido, a construção textual que se elabora no primeiro capítulo de Infância, em que o narrador representa um diálogo tenso com o que se lhe apresentaria à memória psicológica, sob o véu da distância temporal e dos poucos recursos ainda disponíveis à tenra idade para a apreensão de sujeitos, ações e objetos com que interagira, o que exigiria um esforço de interpretação na tentativa de preencher faltas, de resolver dúvidas, de produzir uma cena minimamente coesa e coerente face ao que seriam os fatos que se procura presentificar com o trabalho de representação.

A proposta que aqui se realiza, portanto, é a de analisar o texto de Infância a partir de perspectiva historiográfica, na linha de trabalhos que se empenharam satisfatoriamente em considerar a obra em questão como fonte de dados, seja para 
caracterizar o gênero que ela constitui e em que se constitui - a autobiografia (ZAGURY, 1982); ou como fonte de dados para a representação histórica de práticas de letramento (SILVA, 2004); como (re)construção do percurso ético do sujeito que produz suas memórias face às injunções dos valores morais de um determinado contexto sócio-histórico (KARPA-WILSON, 2005); ou aos modos de sua recepção face às interpretações políticas que possam ser oferecidas à obra em razão de questões ideológicas. (SADLIER, 2012). Mais especificamente, o diálogo se aproxima da investigação empreendida por Silva (2004) sobre o registro das práticas de letramento realizado em Infância com o trabalho autobiográfico do autor sobre suas memórias.

A continuidade para com a discussão proposta nesses estudos se estabelece quando se questionam os modos como se deva considerar o trabalho estilístico como um dado fundamental para a estruturação do texto em sua participação numa cultura artística literária. Trata-se de observar como, na enunciação literária de Infância, se produzem a representação da escrita e do ensino escolar da escrita, e a caracterização dos sujeitos, dos escopos de abrangência das instituições, das formações discursivas. Nesse sentido, o fato de Infância se caracterizar como uma autobiografia em que sobressai o literário (CÂNDIDO, 1992), antes que enfraquecer a possibilidade de que seu texto se constitua em documento para investigação de caráter historiográfico, a fortalece, pois o trabalho estilístico registra na própria materialidade linguística a história da língua. Infância, portanto, é documento de relevância para a investigação histórica sobre o ensino de língua portuguesa, uma vez que guarda nas escolhas linguísticas que constituem seu texto a produção da memória da língua portuguesa em suas relações com o contexto histórico que se fez representado na narrativa.

Propõe-se considerar, portanto, a orientação da produção literária por objetivos estéticos e estilísticos, previamente, mas não excludentemente, aos históricos, sociais, éticos ou morais. Objetiva-se aproximar a lupa e observar no detalhe da construção do texto as estratégias do autor para a composição de uma peça literária cujo poder de representação se sustenta no trabalho sobre o próprio material da representação, a língua, com seus constituintes prosódicos, morfológicos, sintáticos e históricos (que incluem as relações de variação e de mudança linguística; os elementos do oral e do letrado; a documentação da fala e o trato com o registro da escrita).

Estilo se definiria como a escolha realizada pelo sujeito dentre recursos linguísticos oferecidos pela língua, porém considerando-se tal processo a partir de uma perspectiva não psicológica, não pautada na individualidade, mas discursiva. (POSSENTI, 1993). Assim, compreende-se estilo como recurso a uma memória discursiva, a uma memória histórica, associada a uma tomada de posição do sujeito, com os efeitos que essa tomada produz, de modo a obter-se 
um efeito de singularidade no trabalho com o que é da história e da cultura. (POSSENTI, 2007).

Nesse sentido, apoiando-se em fundamentação teórica própria à Análise do Discurso de linha francesa, neste estudo observa-se o texto de autoria de Graciliano Ramos considerando-se os modos de concorrência entre o discurso pedagógico, o religioso, o científico e o literário, e suas funções para o desenvolvimento da narrativa em questão. Em Infância, o autor trabalha com as ambivalências que se produzem quando não estão estabilizados os mecanismos de controle discursivo que estabeleçam referenciais para a compreensão e a interpretação; e quando não estão estabelecidas as fronteiras entre espaços sociais de um modo que existam balizas institucionais para os movimentos dos sujeitos.

A análise proposta consiste em caracterizar quais os recortes operados, pelo autor, no momento de delimitar um espaço de inter-relação entre discursos (MAINGUENEAU, 2005), e a possibilidade, assim, de representar de que modo se estabeleceram as posições de sujeito, os objetos de discurso e os espaços e tempos (nesse caso, para a representação de espaços de ensino e de aprendizagem na indefinição das fronteiras entre lugares sociais diversos - a família, a escola, o comércio -, e entre discursos diversos - o pedagógico, o religioso, o científico, o literário). Considera-se que o texto guarda em sua materialidade índices de suas condições de produção, com o que, da análise textual, se produz acesso à análise discursiva. (ADAM, 2008).

Com o objetivo de ampliar os conhecimentos sobre os processos históricos de formação da escolarização e do ensino de língua portuguesa no Brasil, portanto, pretende-se observar, com base em análise da materialidade textual de Infância, a representação dos processos de institucionalização escolar e da educação linguística, em face da heterogeneidade cultural e da mudança política, num momento específico da história brasileira (a passagem do Império à República, em fins do século XIX), e numa região determinada, distante dos grandes centros econômicos do país (no interior do Nordeste brasileiro, nos Estados de Pernambuco e de Alagoas). Trata-se, nesse caso, de um contexto em que a heterogeneidade se evidencia mais fortemente face aos mecanismos institucionais de controle dos discursos e das práticas.

\section{A constituição de uma memória do ensino de língua portuguesa: o trabalho estilístico em Infância}

A princípio, parte dos textos que vieram a compor os capítulos de Infância foi publicada esparsamente, em jornais, tendo sido reunida em uma unidade 
coesa e coerente posteriormente, a partir do projeto que então surge a Graciliano Ramos de escrever suas memórias. Não se produziram seus primeiros textos, entretanto, segundo seu autor, sob o projeto de comporem um livro. A ideia do livro lhe teria vindo posteriormente, com o que então organizou o material já existente, a que se somaram novas partes. O capítulo "Os astrônomos", em que se focalizarão as considerações aqui realizadas, foi publicado anteriormente à sua presença em Infância, e dele, juntamente com o capítulo "Samuel Smiles", ambos publicados primeiramente em jornal, teria se originado a Graciliano Ramos a ideia de compor um livro de memórias. (Sobre a gênese de Infância, cf.: SILVA, 2004, p. 52 e seguintes; SALLA; LEBENSZTAYN, 2014).

No capítulo em questão, narra-se o episódio acontecido numa "noite extraordinária", quando o pai do narrador se propõe a realizar com o filho a leitura de um livro, monitorando suas dificuldades de decodificação do escrito, e traduzindo "em linguagem de cozinha diversas expressões literárias"; tal projeto de ensino da leitura é abandonado pelo próprio pai, nas noites seguintes, o que frustra o filho em seu interesse iniciado para a narrativa, e reafirma a este o fato de que, aos nove anos, ainda não sabia ler.

O episódio descrito, centro do capítulo "Os astrônomos", se encontra delimitado por um enquadramento em que se caracterizam, na parte inicial, as condições de ensino na escola que o menino, agora narrador, frequentava, e como essas condições mantinham o seu não aprendizado das letras; e, na parte final, o momento em que o menino tenta superar a desilusão causada pelo pai, o pedido de ajuda à prima Emília, que procura convencê-lo a tentar ler com seus próprios recursos. É sobre a parte referente a esse enquadramento, em que se condensa um exaustivo trabalho estilístico do autor sobre a materialidade linguística para a representação literária, que a análise aqui realizada se concentrará. Trata-se de passagem em que o retorno do escritor sobre a forma, o trabalho sobre os recursos linguísticos disponíveis ao poético e a produtividade alcançada sobre as possibilidades expressivas constitutivas da própria linguagem verbal, tomada enquanto instrumento e objeto, concretizam uma peça ímpar da criação literária. $\mathrm{Na}$ elaboração formal e estilística que compõe o texto em questão, representa-se o que seriam o espaço escolar e o ensino de língua portuguesa nas memórias de Infância.

Nelas, no interior dos espaços nomeados como casa ou como escola, alternam-se imprevisivelmente fazeres cotidianos relacionados à subsistência econômica e aos saberes escolares; alternam-se dizeres de moralidade, fatos de religião, dados de ciência, referências ao literário.

Passado, presente e futuro comparecem de modos aparentemente indistintos nesses espaços, que se constituem em realidades a partir da própria vivência dos sujeitos. Estes, em seus movimentos, simbolizam seus fazeres e 
saberes a partir de formas de representação associadas ao contexto imediato de interação, isto é, formas de representação cuja historicidade não é acessada pelos sujeitos. Saber e ignorância se lhes confundem, então, uma vez que não podem precisar historicamente as fontes a que remetem seus dizeres, que são dados à existência a partir de uma memória não sistematizada, não documentada: nem por mecanismos de registro próprios à oralidade, nem por mecanismos de registro próprios à escrita.

A escola de que participara o narrador é já de saída contraposta a uma situação que poderia ser caracterizada como positiva:

Aos nove anos, eu era quase analfabeto. E achava-me inferior aos Mota Lima, nossos vizinhos, muito inferior, construído de maneira diversa. Esses garotos, felizes, para mim eram perfeitos: andavam limpos, riam alto, frequentavam escola decente e possuíam máquinas que rodavam na calçada como trens. Eu vestia roupas ordinárias, usava tamancos, enlameava-me no quintal, engenhando bonecos de barro, falava pouco. (RAMOS, [1945] 1981, p. 199).

A escola frequentada pelo narrador, por comparação à escola frequentada pelos Mota Lima, é marcada assim como não decente, destinada a seres não perfeitos, mas a seres inferiores, inferioridade com que se autocaracteriza o próprio narrador também por meio da comparação. Faz-se presente, já desde o parágrafo inicial do capítulo, o jogo que se constrói na narrativa entre o alto e o baixo, o super e o infer, o perfeito e o imperfeito - e, mais adiante nesse capítulo, entre o céu (da religião), o céu da ciência e a terra dos sujeitos comuns.

A escola descrita, diversamente do que se planejava para seus modos de institucionalização no projeto republicano, em que demarcaria os limites entre o privado e o público (LIMA; PINHEIRO, 2008), ocupa no espaço uma posição limítrofe (a tematização dos limites, como referido, é constitutiva do texto em análise), que se representa pela própria localização geográfica em que se encontraria - uma escola de ponta de rua:

Na minha escola de ponta de rua, alguns desgraçadinhos cochilavam em bancos estreitos e sem encosto, que às vezes se raspavam e lavavam. Nesses dias nós nos sentávamos na madeira molhada. A professora tinha mãe e filha. A mãe, caduca, fazia renda, batendo os bilros, com a almofada entre as pernas. A filha, mulata sarará enjoada e enxerida, nos ensinava as lições, mas ensinava de tal forma que percebemos nela tanta ignorância 
como em nós. Perto da mesa havia uma esteira, onde as mulheres se agachavam, cortavam panos e cosiam. (RAMOS, [1945] 1981, p. 199-200).

Os alunos se caracterizam aí como desgraçadinhos, os que não mereceram a graça, com o que novamente se faz referência a elemento do discurso religioso. Essa referência será retomada na sequência do texto, na continuidade da caracterização desse contexto como algo relacionado a um mundo inferior, ao mais baixo, ao infer. Destaca-se, porém, neste momento, o fato de, na escola, encontrarem-se a professora, mas também, junto a ela (e à peça de mobília que comporia o ambiente escolar, a mesa), suas próprias mãe e filha, posicionadas sobre uma esteira. $\mathrm{O}$ ambiente escolar se confunde então com o ambiente domiciliar, em que três gerações de mulheres convivem e realizam trabalhos outros que não o pedagógico, mas o relacionado a atividades manuais com que se obteriam recursos para o sustento das pessoas envolvidas.

A função mesma da professora é colocada em questão nesse lugar em que o profissional e o pessoal se encontram, em que a instituição escolar não se mostra segundo limites bem definidos que a diferenciassem do cotidiano familiar, que incluiria, nesse caso, as atividades manuais de subsistência. Na "professora" - esse é um caso do uso de aspas (AUTHIER-REVUZ, 2004), pois, segundo o posicionamento que se assuma, ela é e não é professora - se percebia tanta ignorância como nos alunos, fato que, mais uma vez, assinala a ausência de diferenças entre os espaços e os sujeitos que os ocupam. O contexto seria caracterizado pela horizontalidade, em que as posições ocupadas pelos sujeitos não se hierarquizariam pelo atravessamento de uma presença institucional (a "escola" ao mesmo tempo é e não é escola). Essa horizontalidade se mostra na própria construção do cenário em observação: professora, sua mãe, sua filha e alunos se distribuem no espaço em paralelo - ao lado da mesa, a esteira; em frente a essas, os bancos estreitos e sem encosto. Não há verticalidades que imponham descontinuidades ao espaço, sejam essas descontinuidades simbólicas, sejam materiais.

No texto, essa indistinção é representada linguisticamente também com base no trabalho sobre o léxico e sua relação com elementos da memória inscrita na língua. Na passagem reproduzida a seguir, mais uma vez se confundem enunciados próprios ao contexto escolar - a pronúncia de uma palavra encontrada numa seleta -, com enunciados próprios ao contexto privado, familiar - as questões de namoro da filha, que compartilhava em seus afazeres manuais o espaço e as práticas da "sala de aula". É em meio a essa indistinção de contextos e funções que os envolvidos discutem sobre a forma correta de uma determinada palavra: 
D. Agnelina rezingava com a filha por questões de namoro e, em caso de necessidade, administrava-lhe corretivos. Uma vez discutiram a respeito da palavra auréola, que surgiu na minha seleta. A moça acertou, mas d. Agnelina, debruando um vestido, julgou auréola equivalente a debrum, estirou o beiço e, depois de hesitar, misturando baixinho auréola com ourela, recomendou-me que, para evitar dúvidas, dissesse aureóla. (RAMOS, [1945] 1981, p. 203).

Na passagem acima é então nomeada a "professora": Agnelina, nome em que a referência ao religioso pode novamente se entrever na reunião da palavra agnus - palavra latina utilizada na religião cristã para referir Cristo como o cordeiro de Deus -, com o sufixo -ina, que, também do latim, significa "da natureza de; feito de; como".

A professora, com essas remissões em seu nome, discute justamente o modo como deveria ser pronunciada a palavra auréola, dúvida que indica, no fato do não domínio da forma fonética do vocábulo, seu desconhecimento e, junto ao desconhecimento da palavra, a não familiaridade com o discurso religioso (e as práticas discursivas próprias a ele e suas instituições) em que principalmente (mas não só) a palavra em questão é recorrente. A nomeação do sujeito - da professora Agnelina - não corresponde, portanto, à sua relação com as práticas discursivas a que se filia a própria escolha de seu nome. Nota-se, novamente, a caracterização de um contexto em que coexistem de modo não articulado práticas e discursos, ou mesmo práticas, discursos e instituições. Os sujeitos não possuem referências simbólicas que lhes possibilitem localizar-se em meio aos elementos que compõem uma cultura que exceda seus contextos imediatos de interação. Os acontecimentos se pautam pela indistinção, pela indiferenciação, e são condicionados por uma memória histórica que não é acessível objetivamente para os sujeitos que dela participam. A escola descrita não é a escola modernizada pelos grupos escolares do projeto republicano, mas a que guarda em si as características das escolas sem controle de um Sistema Nacional de Ensino (LIMA; GATTI JR, 2008; LIMA; PINHEIRO, 2008).

Esse condicionamento sem possibilidade da simbolização de seu próprio processo pelos sujeitos é então representado no trabalho narrativo sobre a palavra auréola. Confundida com debrum, termo mais presente no cotidiano dos afazeres manuais de costureira, auréola é relacionada então à ideia de limite, sentido que compõe, de acordo com o Dicionário Houaiss. (HOUAISS, 2012, não paginado).

O problema dos limites (ou da imprecisão destes), questão central do capítulo em análise, é então representado, no texto, na própria construção 
narrativa em torno da forma linguística, e de modo a mostrar um processo de produção de conhecimentos que escapa ao controle dos sujeitos - dado que não possuiriam recursos simbólicos para tanto -, mas que, ainda assim, acontece no fazer de uma memória histórica que se constitui na inter-relação entre discursos cujos limites não se demarcam claramente. Na discussão sobre a forma de auréola, a forma final escolhida por D. Agnelina, aureóla, não é a correta para os usos correntes do momento histórico em que os fatos se passavam, mas tanto a alternância na quantidade da sílaba (aurěolalaureŏlus $(u m)(a)$ ), quanto a alternância na tonicidade (na derivação de palavras portuguesas a partir de palavras latinas), são previstas na história da língua, como se pode observar na apresentação encontrada no verbete do Dicionário Houaiss (HOUAISS, 2012, não paginado), principalmente no item etimologia:

1 círculo dourado ou peça de metal circular com que pintores e escultores circundam muitas vezes a cabeça de Cristo, da Virgem e dos santos; resplendor; 2 Rubrica: astronáutica. círculo luminoso ou colorido que circunda um astro quando de sua passagem por zona próxima ao Sol; 3 Derivação: por extensão de sentido. qualquer círculo luminoso; luz resplandecente; clarão; 4 Derivação: sentido figurado. estado de glória; esplendor; 5 Rubrica: geologia. zona periférica a um mineral, formada pela reação química deste com o magma que lhe originou. Locuções. de contato ou de metamorfismo Rubrica: geologia. banda de terreno em torno de maciço eruptivo em que incidiram ações metamórficas originadas pela intrusão de rochas magmáticas. Etimologia substv. do fem. aurěola do adj. lat. aureŏlus, a, um 'da cor de ouro', p.ext., 'brilhante' (dim. de aurěa); ver aur(i/o)-. Sinônimos halo, nimbo, resplendor. Parônimos aréola (s.f.) e aureola (fl. aureolar). (HOUAISS, 2012, não paginado).

A dúvida da professora quanto à pronúncia da palavra parece não ser então de todo imotivada devido à ignorância. Há algo na memória da palavra que sustenta a possibilidade de alternância, de instabilidade de sua forma.

Nesse sentido, parece que a instabilidade das formas, dos posicionamentos, dos espaços, dos tempos e das funções, se representa, na narrativa, no próprio trabalho realizado, pelo autor, sobre a forma da palavra auréola. E a escolha dessa palavra parece não se fazer, também, de modo motivado apenas pela reminiscência do que produz um texto autobiográfico, mas pelo trabalho estilístico que se propõe metaenunciativo: considerados seus significados principal e derivados, de acordo ainda com o dicionário consultado, observa-se que o vocábulo em questão remete a discursos distintos, os quais estão em jogo no 
processo interdiscursivo representado na narrativa em análise (o mesmo se pode observar para a escolha de "debrum"). Com isso, representa-se, da perspectiva do olhar modernizado pelo ideal republicano, o que seria o ensino de língua portuguesa na escola que guarda traços de sua implementação nos oitocentos. (SCHUELER; MAGALDI, 2009).

Assim, em seu significado primeiramente apresentado ("círculo dourado ou peça de metal circular com que pintores e escultores circundam muitas vezes a cabeça de Cristo, da Virgem e dos santos; resplendor"), auréola guarda seu sentido em referência a um modo de representação do discurso religioso. Referência a esse discurso é encontrada também na indicação da derivação para sentido figurado: "estado de glória; esplendor".

Ainda nas acepções derivadas, guarda rubricas relacionadas à astronáutica ("círculo luminoso ou colorido que circunda um astro quando de sua passagem por zona próxima ao Sol”), e à geologia (“zona periférica a um mineral, formada pela reação química deste com o magma que lhe originou"; e "banda de terreno em torno de maciço eruptivo em que incidiram ações metamórficas originadas pela intrusão de rochas magmáticas"). Ou seja: em seus sentidos principal e derivados, a palavra auréola guarda as referências ao alto e ao baixo, e ao limítrofe (observe-se a relação que se estabelece, no texto, entre a auréola da seleta e o debrum das costuras), a que o autor refere para a estruturação dos sentidos em seu texto.

Desse modo, auréola, no texto, aproxima significações advindas do discurso religioso, mas também do científico. Nesse processo de referenciação, remete a uma verticalidade que ordena elementos do céu, sejam os da astronáutica, sejam os da religião, e elementos da terra, sejam os da geologia, sejam os da religião.

Quanto ao céu, que se recorda no título do texto, "Os astrônomos", é retomado na terceira parte desse capítulo, quando o narrador recorre à prima para auxiliá-lo com a continuidade da leitura do livro em que o pai o iniciara e, logo, por fim, o abandonara:

Emília respondeu com uma pergunta que me espantou. Por que não me arriscava a tentar a leitura sozinho?

Longamente lhe expus a minha fraqueza mental, a impossibilidade de compreender as palavras difíceis, sobretudo na ordem terrível em que se juntavam. Se eu fosse como os outros, bem; mas era bruto em demasia, todos me achavam bruto em demasia.

Emília combateu a minha convicção, falou-me dos astrônomos, indivíduos que liam no céu, percebiam tudo quanto há no céu. Não no céu onde moram Deus Nosso Senhor e a Virgem Maria. Esse ninguém tinha visto. Mas o outro, o que fica por baixo, o do sol, da lua e das estrelas, 
os astrônomos conheciam perfeitamente. Ora, se eles enxergavam coisas tão distantes, por que não conseguiria eu adivinhar a página aberta diante dos meus olhos? Não distinguia as letras? Não sabia reuni-las e formar palavras? (RAMOS, [1945] 1981, p. 203).

Na passagem acima, a própria Emília faz a distinção entre o céu da religião e o outro, o que fica por baixo, lido pelos astrônomos. Discurso religioso e da ciência se limitam nas palavras da personagem - ela mesma caracterizada pelo narrador como alguém que "não era deste mundo", "um anjo" -, e se hierarquizam: o céu da religião fica acima do céu dos astrônomos, abaixo do qual se encontram os elementos da terra, em que se engenham bonecos de barro (o mesmo barro de que se fez Adão?), ou em que os sujeitos se imobilizam, aproximando-se da morte (simbólica?), numa situação que aterra:

O lugar de estudo era isso. Os alunos se imobilizavam nos bancos: cinco horas de suplício, uma crucificação. Certo dia vi moscas na cara de um, roendo o canto do olho, entrando no olho. E o olho sem se mexer, como se o menino estivesse morto. Não há prisão pior que uma escola primária do interior. A imobilidade e a insensibilidade me aterrraam. Abandonei os cadernos e as auréolas, não deixei que as moscas me comessem. Assim, aos nove anos ainda não sabia ler. (RAMOS, [1945] 1981, p. 200).

Note-se o duplo sentido que obtém o termo "aterrar" na construção elaborada, ao longo do capítulo, com a hierarquização entre o que é do céu da religião, do céu da ciência, e da terra: em seu temor por se enterrar, o narrador não se deixa ir ainda a um lugar mais baixo na hierarquia simbólica de que participa.

A primeira parte do capítulo se encerra, portanto, com a (in)definição do "lugar de estudo": sequer nomeado de escola - é posto como equivalente piorado de outra instituição, a prisão -, nesse momento da narrativa o espaço de ensino se reduz a algo referido por isso, demonstrativo que não precisa o elemento a que se faz referência. Nesse espaço, não se cumprem as prerrogativas do pedagógico escolar, mas as prerrogativas de um determinado discurso religioso - do suplício e da crucificação. O espaço escolar é associado, por fim, ora a um lugar de ausência de vida, ora a um local de aprisionamento, mas, num caso e noutro, a um lugar de morte do simbólico, de impossibilidade de simbolização. Em lugar de promover a aprendizagem, impossibilita-a: “Assim, aos nove anos ainda não sabia ler". 


\section{A escola, a língua e a produção de uma memória}

Em “Os astrônomos", se há uma hierarquização dos espaços, que vai do céu da religião, descendo ao céu dos astros, para chegar à terra, que pode, no limite, aterrar, essa ordem - representada em sua verticalidade no campo semântico da palavra auréola, que nucleia a elaboração textual observada - não se institui no espaço do escolar do interior do Nordeste brasileiro, em fins do Império e início da República. Nesse espaço, família e docência, domicílio e sala de aula, manufatura e ensino ocupam o mesmo local, em que os discursos se produzem sem que se estabeleça relação sistematizada com uma memória histórica que se apresente como uma tradição - existente, ou por se fazer (HOBSBAWN; RANGER, 2002), ou, num outro sentido, com um projeto de Educação, seja ele o dos oitocentos, no Império, seja ele o da República. (SCHUELER; MAGALDI, 2009). Os limites não se colocam, então, de modo preciso, definido, associados a algum tipo de hierarquia que é própria dos processos institucionais.

Os saberes e os fazeres da "sala de aula" se orientam por filiações discursivas imprevistas, num processo interdiscursivo em que os sentidos deslizam horizontalmente de uma formação discursiva a outra, guardando, num mesmo espaço, elementos do religioso, do pedagógico, do cotidiano familiar.

A ausência do normativo institucional, no entanto, não indicaria simples e rasamente a existência da ignorância, dado que na memória inscrita nas palavras, no processo de negociação dos sentidos em face de uma cultura escolar-como na discussão ensejada pela seleta -, se faria responder o sentido guardado por uma tradição fundamentada nas práticas de oralidade e nos movimentos que a caracterizam. Assim, nessa terra em que os sujeitos se movimentam, a ordem se sustentaria nos sentidos das palavras, na memória histórica inscrita nesses sentidos, base em que a escrita literária torna possível a representação dos processos de escolarização e de ensino de língua portuguesa face à heterogeneidade cultural de um momento histórico e de um lugar regional específicos. A autobiografia sustentada no literário, "verdade da memória feita linguagem" (BARROS, 2006, p. 226), permite que as bases orais das práticas de ensino sejam reescritas segundo as regras do estilo da cultura letrada. Dos documentos resultantes desse processo de letramento se podem produzir dados que evidenciem características de um momento histórico anterior, representado, e, por contraste, de um momento histórico posterior, a partir de onde se produz a representação.

No contexto de Infância, para a representação da ausência ou da fragilidade das instituições, entre elas, a escolar, a língua se constitui em referência institucional primeira. As diferentes formas que a oralidade não informada pelo 
escrito deixa reaparecer, retornar, por vezes sob o estigma do erro, elas mesmas, essas formas, esconderiam, no passado de sua variação, outros sentidos, que a formalização, a institucionalização e a oficialização de certos registros legitimados se esforçam por fazer esquecer. O trabalho literário, no entanto, ao informar estilisticamente as formas da língua, mesmo as estigmatizadas, produz, nesse trabalho mesmo, uma memória que se pode acessar com o objetivo de conhecer o processo histórico de constituição da educação linguística no país.

\section{REFERÊNCIAS}

ADAM, J.-M. A linguística textual: introdução à análise textual dos discursos. Revisão técnica de: Luis Passeggi e João Gomes da Silva Neto. São Paulo: Cortez, 2008.

AUTHIER-REVUZ, J. Heterogeneidade mostrada e heterogeneidade constitutiva: elementos para uma abordagem do outro no discurso. In: AUTHIER-REVUZ, J. Entre a transparência e a opacidade: um estudo enunciativo do sentido. Porto Alegre: EDIPUCRS, 2004.

BARROS, M. L. P. de. A arquitetura das memórias: um estudo do tempo no discurso autobiográfico. 233 f. Dissertação (Mestrado em Linguística) - Faculdade de Filosofia, Letras e Ciências Humanas, Universidade de São Paulo, São Paulo, 2006.

CANDIDO, A. Ficção e confissão: ensaios sobre Graciliano Ramos. Rio de Janeiro: Ed. 34, 1992.

HOBSBAWN, E. J.; RANGER, T. (Orgs.). A invenção das tradições. 3. ed. Rio de Janeiro: Paz e Terra, 2002.

HOUAISS, A. Grande Dicionário Houaiss da Língua Portuguesa on-line. 2012. Disponível em: <http://houaiss.uol.com.br/>. Acesso em: jul. 2014.

KARPA-WILSON, S. The ethical self in Graciliano Ramos' Infância. Luso-Brazilian Review. Madison - University of Wisconsin, n. 42, v. 1, p. 154-178, 2005.

LIMA, G. G. de; GATTI JR, D. Entre Escolarização e Instituições Escolares na Historiografia da Educação: a emergência dos grupos escolares no Brasil da República Velha (1889-1930). Série-Estudos (UCDB), v. 25, p. 67-84, 2008.

LIMA, R. C.; PINHEIRO, A. C. F. O Ensino público paraibano na transição do Império para República: a "educação popular" e a "educação para todos". In: ENCONTRO ESTADUAL DA ANPUH - PB - História e historiografia: Entre o Nacional e o Regional, XIII., 2008, Campina Grande. Anais... Campina Grande: EDUFCG, 2008. v. 1. p. 1-15. 
MAINGUENEAU, D. Gênese dos discursos. Tradução de: Sírio Possenti. Curitiba, PR: Criar Edições, 2005.

MORTATTI, M. do R. L. Os sentidos da alfabetização: São Paulo - 1876/1994. São Paulo: Ed. UNESP; Brasília: MEC/INEP/COMPED, 2000.

PIETRI, E. A constituição da escrita escolar em objeto de análise dos estudos linguísticos. Trabalhos em Linguística Aplicada, v. 46, p. 283-297, 2007.

PIETRI, E. Sobre a constituição da disciplina curricular de língua portuguesa. Revista Brasileira de Educação, n. 43, v. 15, p. 70-83, 2010.

POSSENTI, S. Discurso, estilo e subjetividade. São Paulo: Martins Fontes, 1993.

POSSENTI, S. Ensinar estilo? Calidoscópio, São Leopoldo: Unisinos, v. 5, n. 1, p. 1923, jan./abr. 2007.

RAMOS, G. Infância. Posfácio de: Octávio de Faria. Ilustrações de: Darcy Penteado. 17. ed. Rio de Janeiro: Record, 1981.

SADLIER, D. J. Lendo Graciliano Ramos nos Estados Unidos. Revista do Instituto de Estudos Brasileiros, São Paulo, n. 54, p. 31-52, 2012.

SALLA, T. M.; LEBENSZTAYN, I. (Orgs.). Conversas. Rio de Janeiro: Record, 2014.

SCHUELER, A. F. M.; MAGALDI, A. M. B. M. Educação escolar na primeira república: memória, história e perspectivas de pesquisa. Tempo [on-line], v. 13, n. 26, p. 32-55, 2009.

SILVA, M. C. da. Infância, de Graciliano Ramos: uma história da formação do leitor no Brasil. 196 f. Tese (Doutorado em Teoria e História Literária) - Instituto de Estudos da Linguagem, Universidade Estadual de Campinas, 2004.

SOARES, M. Português na escola: história de uma disciplina curricular. In: BAGNO, M. (Org.). Linguística da norma. São Paulo: Loyola, 2002.

VIDAL, D. G. 80 anos do Manifesto dos Pioneiros da Educação Nova: questões para debate. Educação e Pesquisa [on-line], v. 39, n. 3, p. 577-588, 2013.

VIDAL, D. G. No interior da sala de aula: ensaio sobre cultura e prática escolares. Currículo sem fronteiras, v. 9, n. 1, p. 25-41, jan./jun. 2009.

ZAGURY, E. A escrita do Eu. Rio de Janeiro: Civilização Brasileira, 1982.

Texto recebido em 03 de fevereiro de 2015. Texto aprovado em 14 de junho de 2015. 